\title{
In Situ Process Control of Trilayer Gate-Stacks on p-Germanium With 0.85-nm EOT
}

\author{
Y. X. Zheng, A. Agrawal, Member, IEEE, G. B. Rayner, Jr., M. J. Barth, Student Member, IEEE, \\ K. Ahmed, Senior Member, IEEE, S. Datta, Fellow, IEEE, and R. Engel-Herbert
}

\begin{abstract}
In situ spectroscopic ellipsometry was utilized in an atomic-layer-deposition (ALD) reactor for rapid and rational gate stack process optimization of the trilayer dielectric $\mathrm{HfO}_{2} / \mathrm{Al}_{2} \mathrm{O}_{3} / \mathrm{GeO}_{x}$ on Ge. The benefit of this approach was demonstrated by developing an entire process in situ: 1) native oxide removal by hydrogen plasma; 2 ) controlled reoxidation for Ge surface passivation; and 3) deposition of $\mathrm{Al}_{2} \mathrm{O}_{3}$ and $\mathrm{HfO}_{2}$ using thermal ALD. The low- $k$ layer thicknesses were scaled down without losing their respective functions, i.e., $\mathrm{GeO}_{x}$ to form an electrically well behaved interface with $\mathrm{Ge}$ and $\mathrm{Al}_{2} \mathrm{O}_{3}$ to thermodynamically stabilize the $\mathrm{GeO}_{x} / \mathrm{Ge}$ interface. Aggressive equivalent-oxide-thickness scaling of the trilayer stack down to $0.85 \mathrm{~nm}$ with a low gate leakage of $0.15 \mathrm{~mA} / \mathrm{cm}^{2}$ at $V_{\mathrm{FB}^{-}}$ $1 \mathrm{~V}$ was achieved, while preserving a high-quality dielectricsemiconductor interface.
\end{abstract}

Index Terms-Ge, MOSCAP, trilayer, in-situ spectroscopic ellipsometry, interface, ALD, atomic hydrogen clean.

\section{INTRODUCTION}

$\mathbf{T}$ HE development of Germanium (Ge)-channel field effect devices requires the integration of a high permittivity dielectric that forms an electrically well behaved and thermodynamically stable interface with the underlying semiconductor. While a direct high-k/Ge interface showed a high interface state density $\left(D_{\mathrm{it}}\right)[1], \mathrm{GeO}_{\mathrm{x}} / \mathrm{Ge}$ has been found promising in reducing $D_{\text {it }}$ [2]. However, the equivalentoxide-thickness (EOT) scaling is limited by the low dielectric constant of $\mathrm{GeO}_{\mathrm{x}}(\mathrm{k} \sim 6)$. To scale down EOT, a bilayer gate stack with high-k dielectric on ultrathin $\mathrm{GeO}_{\mathrm{x}}$ has been demonstrated, albeit with high gate leakage and a high trap density at the interface [3], attributed to the high- $\mathrm{k} / \mathrm{GeO}_{\mathrm{x}}$ intermixing caused by the inherent thermodynamic instability of $\mathrm{GeO}_{\mathrm{x}} / \mathrm{Ge}$ interface [4], [5]. Although the utilization of an ultrathin Si layer to shift the dielectric-semiconductor (D-S) interface from $\mathrm{Ge}$ into $\mathrm{Si}$ has been successfully demonstrated [6], the introduction of a planar thin Si layer is incompatible with a 3D FinFET manufacturing process flow.

Manuscript received June 4, 2015; revised July 12, 2015; accepted July 19, 2015. Date of publication July 22, 2015; date of current version August 21, 2015. This work was supported by Intermolecular Inc. The review of this letter was arranged by Editor J. Cai.

Y. X. Zheng, M. J. Barth, S. Datta, and R. Engel-Herbert are with the Pennsylvania State University, State College, PA 16802 USA (e-mail: rue2@psu.edu).

A. Agrawal was with the Department of Electrical Engineering, Pennsylvania State University, State College, PA 16802 USA. He is now with Intel Corporation, Santa Clara, CA 95054-1549 USA.

G. B. Rayner, Jr., is with Kurt J. Lesker Company, Pittsburgh, PA 15025 USA.

K. Ahmed was with Intermolecular Inc., San Jose, CA 95134 USA. He is now with Intel Corporation, Santa Clara, CA 95054-1549 USA

Color versions of one or more of the figures in this letter are available online at http://ieeexplore.iee.org.

Digital Object Identifier 10.1109/LED.2015.2459663
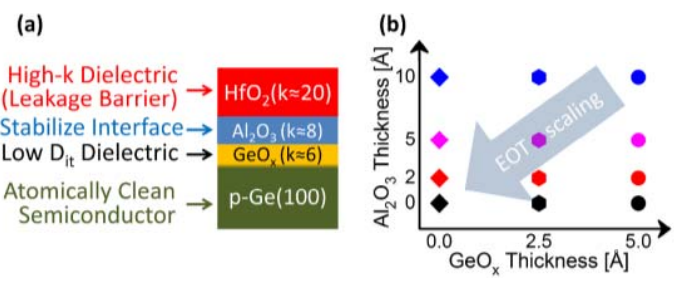

Fig. 1. (a) The design of the trilayer gate stack on p-Ge. (b) Parameter space for EOT scaling of the trilayer gate stacks, with $\mathrm{HfO}_{2}$ kept constant to $\sim 24 \AA$

The pronounced high- $\mathrm{k} / \mathrm{GeO}_{\mathrm{x}}$ intermixing can be effectively reduced by introducing an $\mathrm{Al}_{2} \mathrm{O}_{3}$ diffusion-controllayer (DCL) between $\mathrm{HfO}_{2}$ and $\mathrm{GeO}_{\mathrm{x}}$ [3]. Optimization of such a trilayer gate stack is time consuming and expensive. Immediate feedback during the deposition process and a direct correlation with device performance/characteristics is highly desirable, accelerating the development and rapid prototyping of an entire complex gate dielectric processes.

In this work, we present an in-situ controlled process flow to address this challenge for Ge MOSCAPs. Utilizing in-situ spectroscopic ellipsometry (SE), a $\mathrm{HfO}_{2} / \mathrm{Al}_{2} \mathrm{O}_{3} / \mathrm{GeO}_{\mathrm{x}}$ trilayer gate stack on p-Ge(100) was developed [Fig. 1(a)], including (i) in-situ plasma clean to prepare atomically flat and pristine $\mathrm{Ge}$ surface, (ii) in-situ passivation with $\mathrm{GeO}_{\mathrm{x}}$ to form a low $D_{\text {it }}$ interface, (iii) $\mathrm{Al}_{2} \mathrm{O}_{3}$ ALD deposition to stabilize the interface, and (iv) high-k $\mathrm{HfO}_{2}$ ALD deposition to suppress leakage current. This approach is not limited to $\mathrm{Ge}$ but may be also applicable to other semiconductors forming thermodynamically unstable but passivation-friendly interfaces with high-k dielectrics, such as compound semiconductors [7].

\section{EXPERIMENTAL METHOD}

The design of $\mathrm{HfO}_{2} / \mathrm{Al}_{2} \mathrm{O}_{3} / \mathrm{GeO}_{\mathrm{x}} / \mathrm{p}$-Ge gate stacks is shown in Fig. 1(b). The goal to scale down EOT while maintaining a superior D-S interface was tackled by varying the thicknesses of the low-k $\mathrm{Al}_{2} \mathrm{O}_{3}$ and $\mathrm{GeO}_{\mathrm{x}}$ layers without losing their respective functions. The $\mathrm{HfO}_{2}$ layer thickness was fixed $(\sim 24 \AA)$ to limit the number of experimental variables.

Fig. 2 shows an overview of the p-Ge MOSCAPs process flow using $\mathrm{HfO}_{2} / \mathrm{Al}_{2} \mathrm{O}_{3} / \mathrm{GeO}_{\mathrm{x}}$ gate stacks. Details of the optimization of individual process steps will be discussed further below. First, p-Ge(100) substrates (Ga-doped, resistivity $=1.0-5.0 \Omega / \mathrm{cm}$, by Umicore Electro-Optic Materials) were degreased with acetone, isopropyl-alcohol and de-ionized water rinses. The substrates were immediately transferred into the load-lock of ALD system (Kurt J. Lesker Company ALD-150LX). The following process steps in ALD chamber were monitored by in-situ SE (M-2000U, 


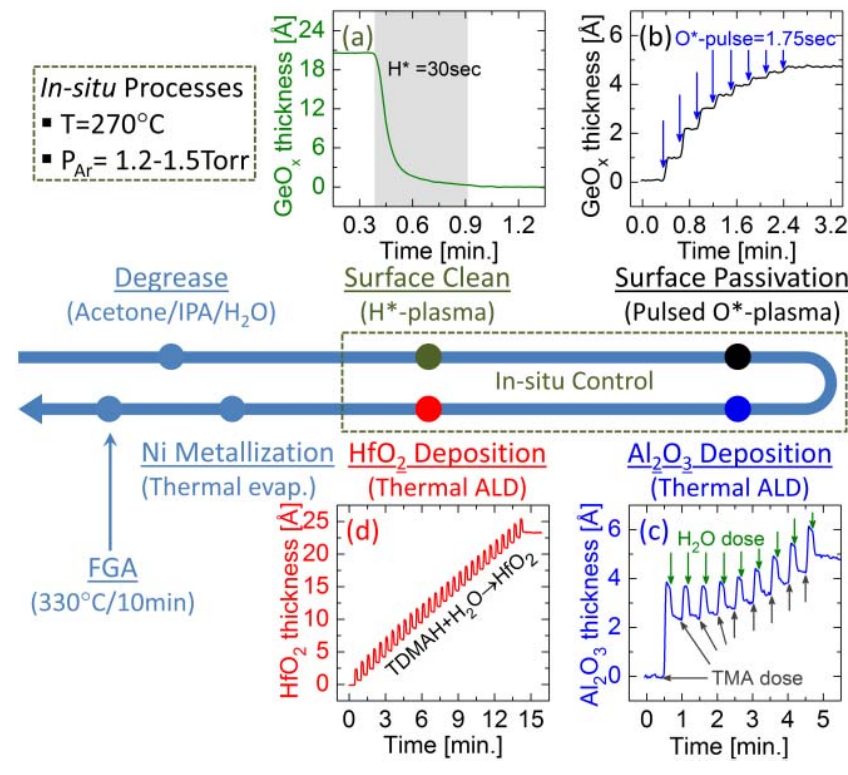

Fig. 2. In-situ SE monitoring of the fabrication process: (a) $\mathrm{H}^{*}$-plasma clean of native $\mathrm{GeO}_{\mathrm{x}}$, (b) $\mathrm{Ge}$ passivation by pulsed $\mathrm{O}^{*}$-plasma, (c) $\mathrm{Al}_{2} \mathrm{O}_{3}$ thermal ALD, and (d) $\mathrm{HfO}_{2}$ thermal ALD, with all oxides described as Cauchy model.

J. A. Woollam), which monitors the dielectric function of samples, providing real-time information of surface modification like deposition and etching. Figs. 2(a)-(d) show an example of in-situ SE monitoring the trilayer gate stack development $\left(270{ }^{\circ} \mathrm{C}\right.$, background $p_{\text {Ar }}=1.2-1.5$ Torr $)$. The residual native $\mathrm{GeO}_{\mathrm{x}}$ was effectively removed by in-situ $\mathrm{RF}$ atomic hydrogen $\left(\mathrm{H}^{*}\right)$ plasma $\left(100 \mathrm{~W}, \mathrm{H}_{2}: \mathrm{Ar}=3: 117 \mathrm{sccm}\right.$, $30 \mathrm{sec}$ ) [Fig. 2(a)]. The $\mathrm{GeO}_{\mathrm{x}}$ passivation layer was grown by oxygen $\left(\mathrm{O}^{*}\right)$ plasma pulses $(125 \mathrm{~W}, 1.75 \mathrm{sec} /$ pulse, $\mathrm{O}_{2}: \mathrm{Ar}=3: 117$ sccm) [Fig. 2(b)]. The $\mathrm{Al}_{2} \mathrm{O}_{3}$ layer was deposited by thermal ALD with tri-methyl-aluminium (TMA) and $\mathrm{H}_{2} \mathrm{O}$ [Fig. 2(c)]. The $\mathrm{HfO}_{2}$ layer was deposited by thermal ALD using tetrakis-dimethyl-amino-hafnium (TDMAH) and $\mathrm{H}_{2} \mathrm{O}$ [Fig. 2(d)]. Each layer thickness in the trilayer gate stacks was precisely controlled by in-situ SE. $60 \mathrm{~nm} \mathrm{Ni}$ was thermally evaporated as the gate metal on the samples, which were then annealed in forming gas $\left(\mathrm{FGA}, \mathrm{H}_{2}: \mathrm{Ar}=20: 1050 \mathrm{sccm}\right.$, $\left.330{ }^{\circ} \mathrm{C} / 10 \mathrm{~min}\right)$.

\section{Results AND Discussion}

\section{A. In-Situ Process Optimization}

The $\mathrm{Ge}$ surface preparation by in-situ $\mathrm{H}^{*}$-plasma showed a strong temperature-dependence. At low temperatures $\left[110{ }^{\circ} \mathrm{C}\right.$, Fig. 3(a)], $\mathrm{H}^{*}$-plasma over-exposure resulted in an unexpected increase in " $\mathrm{GeO}_{\mathrm{x}}$ " thickness. Ex-situ atomic force microscopy (AFM) indicated that the surface was significantly and irreversibly roughened [Fig. 3(a) inset]. The increase in ' $\mathrm{GeO}_{\mathrm{x}}$ ' thickness was attributed to the optical contribution from increased surface roughness as a consequence of surface disordering [8]. A similar effect was also observed on $\mathrm{Si}$ surface [9]. The temperature was too low and pristine Ge surfaces were also etched in $\mathrm{H}^{*}$-plasma. In contrast, extra $\mathrm{H}^{*}$ dose at high temperatures maintained a smooth surface $\left[270{ }^{\circ} \mathrm{C}\right.$, Fig. 3(b) inset] (RMS $=0.294 \mathrm{~nm}$, as compared to $0.295 \mathrm{~nm}$ for degreased substrate before
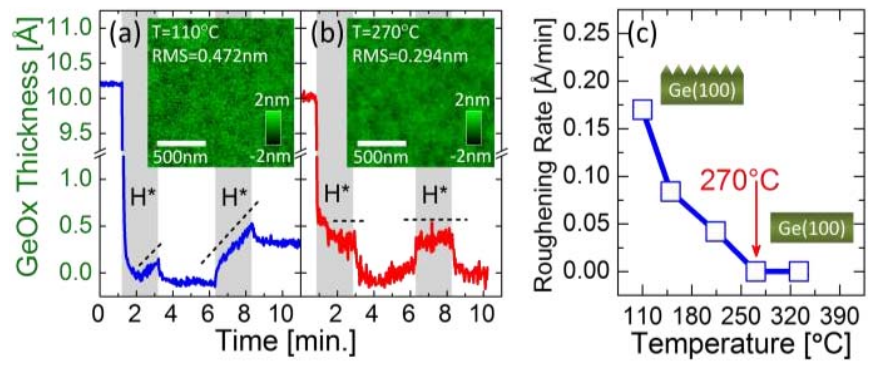

Fig. 3. In-situ SE for $\mathrm{H}^{*}$-plasma (shaded region) at (a) $110{ }^{\circ} \mathrm{C}$ and (b) $270{ }^{\circ} \mathrm{C}$ on $\mathrm{Ge}$; the insets are corresponding ex-situ AFM images after $\mathrm{H}^{*}$-plasma. (c) Ge surface roughening rate by $\mathrm{H}^{*}$-plasma, extracted from in-situ SE using the nominal " $\mathrm{GeO}_{\mathrm{x}}$ " thickness as measure for surface roughness.

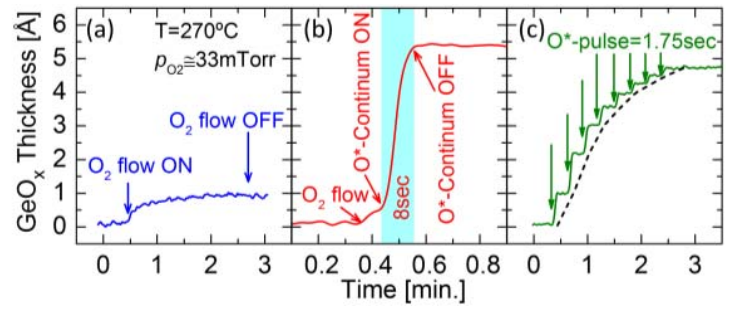

Fig. 4. In-situ SE for three $\mathrm{GeO}_{\mathrm{x}}$ growth modes at $270{ }^{\circ} \mathrm{C}$ : (a) molecular $\mathrm{O}_{2}$ ( $\left.p_{\mathrm{O} 2} \approx 33 \mathrm{mTorr} / 2 \mathrm{~min}\right),(\mathrm{b})$ continuous $\mathrm{O}^{*}$-plasma $(8 \mathrm{sec})$, and (c) sequence of $\mathrm{O}^{*}$-plasma pulses $(1.75 \mathrm{sec} /$ pulse). Note the shorter time scale in (b).

$\mathrm{H}^{*}$-plasma), and caused a reversible increase of the nominal "GeO ${ }_{\mathrm{x}}$ " thickness in SE [Fig. 3(b)], attributed to the local surface heating by plasma exposure. The critical temperature to avoid degradation of $\mathrm{Ge}$ surface in the $\mathrm{H}^{*}$-plasma was found to be at $T_{C} \approx 270{ }^{\circ} \mathrm{C}$, and hence fixed as the optimal temperature throughout the process.

The as-obtained pristine Ge surfaces were then passivated with $\mathrm{GeO}_{\mathrm{x}}$. Three oxidation modes were evaluated: (i) $\mathrm{O}_{2}$ gas, (ii) continuous $\mathrm{O}^{*}$-plasma, and (iii) $\mathrm{O}^{*}$-plasma pulses, as shown in Fig. 4. Exposing the Ge surface to $\mathrm{O}_{2}$ resulted in a slow and limited formation of submonolayer $\mathrm{GeO}_{\mathrm{x}}(\sim 1 \AA)$ [Fig. 4(a)], while the continuous $\mathrm{O}^{*}$-plasma [Fig. 4(b)] caused rapid $\mathrm{Ge}$ oxide formation $(\sim 0.7 \AA / \mathrm{sec})$, not suitable for precise control of the targeted $\mathrm{GeO}_{\mathrm{x}}$ thickness. A pulsed $\mathrm{O}^{*}$-plasma mode was used [Fig. 4(c)], allowing a precise adjustment of $\mathrm{GeO}_{\mathrm{x}}$ thicknesses up to $\sim 5 \AA(\approx 1$ monolayer $)$. The self-limited behaviour was interpreted as a result of the mild oxidation conditions enabled by the short pulses, suggesting that the topmost monolayer of $\mathrm{GeO}_{\mathrm{x}}$ acted as an oxygen protection layer.

\section{B. Electrical Characterization of Trilayer Gate Stacks}

Equipped with the precise thickness information for each dielectric layer from in-situ SE, we investigated their effects on the electrical properties of $\mathrm{HfO}_{2} / \mathrm{Al}_{2} \mathrm{O}_{3} / \mathrm{GeO}_{\mathrm{x}}$ MOSCAPs. The role of $\mathrm{GeO}_{\mathrm{x}}$ was first investigated using p-Ge MOSCAPs of $\mathrm{HfO}_{2}(24 \AA) / \mathrm{Al}_{2} \mathrm{O}_{3}(10 \AA) / \mathrm{GeO}_{\mathrm{x}}$ stack with various $\mathrm{GeO}_{\mathrm{x}}$ thicknesses. The $C-V$ characteristics in Fig. 5 show that the sample with $\sim 5 \AA \mathrm{GeO}_{\mathrm{x}}$ passivation showed a small frequency dispersion in accumulation $\left(\Delta C / C_{\max }=2.3 \%\right)$, indicating an improved D-S interface 


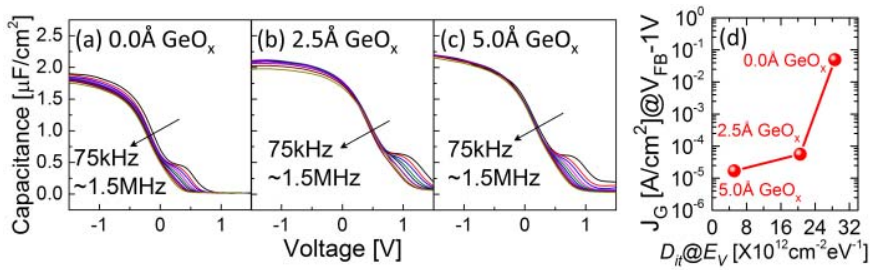

Fig. 5. $\quad C$ - $V$ characteristics of $\mathrm{HfO}_{2}(24 \AA) / \mathrm{Al}_{2} \mathrm{O}_{3}(10 \AA) / \mathrm{GeO}_{\mathrm{x}} / \mathrm{p}-\mathrm{Ge}(100)$ MOSCAPs with varying $\mathrm{GeO}_{\mathrm{x}}$ thickness: (a) 0.0 , (b) 2.5 , and (c) $5.0 \AA$. (d) The effect of $\mathrm{GeO}_{\mathrm{x}}$ thickness on MOSCAP performance. $V_{F B}$ is the flatband voltage, and $E_{V}$ is the valence band edge. $D_{i t} @ E_{v}$ were extracted using Castagne-Vapaille method [11].
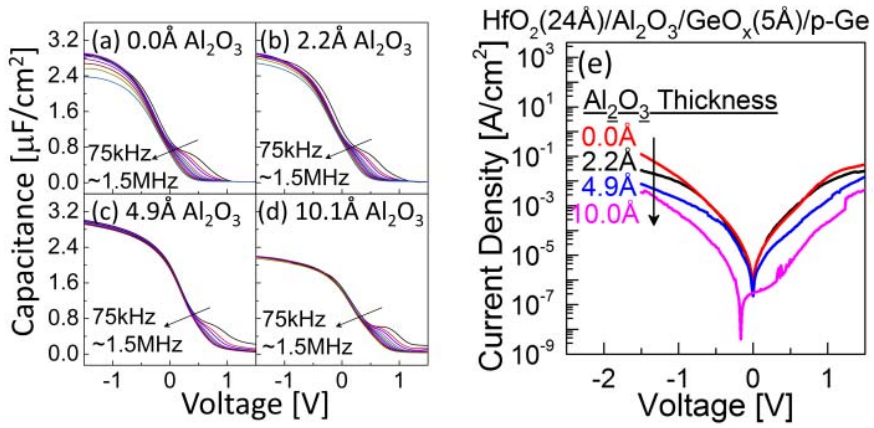

Fig. 6. $C$ - $V$ of $\mathrm{HfO}_{2}(24 \AA) / \mathrm{Al}_{2} \mathrm{O}_{3} / \mathrm{GeO}_{\mathrm{x}}(5 \AA) / \mathrm{p}-\mathrm{Ge}$ MOSCAPs with (a) 0.0 , (b) 2.2 , (c) 4.9 , and (d) $10.1 \AA \mathrm{Al}_{2} \mathrm{O}_{3}$; (e) the corresponding gate leakages.

quality $\left(D_{i t} @ E_{v} \approx 5.1 \times 10^{12} \mathrm{~cm}^{-2} \mathrm{eV}^{-1}\right)$, while an insufficient $\mathrm{GeO}_{\mathrm{x}}$ passivation $(0.0$ and $2.5 \AA$ ) resulted in not only a larger frequency dispersion at accumulation, but also a higher gate leakage $\left(J_{G}\right)$ [Fig. 5(d)]. Thus, we concluded that a minimum $\mathrm{GeO}_{\mathrm{x}}$ thickness of $\sim 5 \AA$ was necessary to create a high-quality interface and to maintain a low gate leakage. The physical mechanism behind this is attributed to that the $\mathrm{GeO}_{\mathrm{x}}$ passivation increased the conformity of $\mathrm{Al}_{2} \mathrm{O}_{3} \mathrm{ALD}$ nucleation (AFM results not shown here), and therefore formed a better quality of the dielectric-Ge interface and reduced defects in the dielectrics.

The effectiveness of the $\mathrm{Al}_{2} \mathrm{O}_{3}$ as DCL was also studied combining in-situ $\mathrm{SE}$ and electrical characteristics. Figure 6 shows the $C$ - $V$ characteristics for $\mathrm{HfO}_{2}(24 \AA) / \mathrm{Al}_{2} \mathrm{O}_{3} / \mathrm{GeO}_{\mathrm{x}}(5 \AA)$ gate stacks with various $\mathrm{Al}_{2} \mathrm{O}_{3}$ thicknesses. As expected, a direct contact between $\mathrm{HfO}_{2}$ and $\mathrm{GeO}_{\mathrm{x}}$ resulted in an inferior D-S interface [Fig. 6(a)]; the $\mathrm{HfO}_{2} / \mathrm{GeO}_{\mathrm{x}}$ intermixing may result in $\mathrm{Hf}-\mathrm{Ge}$ bond formation [5], contributing to the interface and border trap states [3], [5]. In contrast, a use of $\sim 5 \AA \mathrm{Al}_{2} \mathrm{O}_{3}$ DCL well preserved the $\mathrm{GeO}_{\mathrm{x}} / \mathrm{Ge}$ interface quality [Fig. 6(c)], while no further improvement was found for thicker $\mathrm{Al}_{2} \mathrm{O}_{3}[\sim 10 \AA$, Fig. 6(d)]. Another consequence of introducing $\mathrm{Al}_{2} \mathrm{O}_{3}$ DCL is the suppression of gate leakage $\left[J_{G}-V\right.$ in Fig. 6(a)], attributed to the suppression of $\mathrm{HfO}_{2} / \mathrm{GeO}_{\mathrm{x}}$ intermixing and therefore the reduction of electrically active defects in $\mathrm{HfO}_{2}$ [3], [10]. Fig. 7 compiles the characteristics of various gate stacks on $\mathrm{Ge}$ to benchmark the trilayer gate stacks. The Ge p-MOSCAP using the $\mathrm{HfO}_{2}(24 \AA) / \mathrm{Al}_{2} \mathrm{O}_{3}(5 \AA) / \mathrm{GeO}_{\mathrm{x}}(5 \AA)$ gate stack showed the optimum performance, with a sub-nm EOT $(\sim 0.85 \mathrm{~nm})$ and low gate leakage $\left(J_{G}=0.15 \mathrm{~mA} / \mathrm{cm}^{2}\right.$ at $\left.V_{F B}-1 \mathrm{~V}\right)$. We observed that for very thin $\mathrm{Al}_{2} \mathrm{O}_{3}$ layers, both EOT and $J_{G}$ decreased; this can be attributed to an

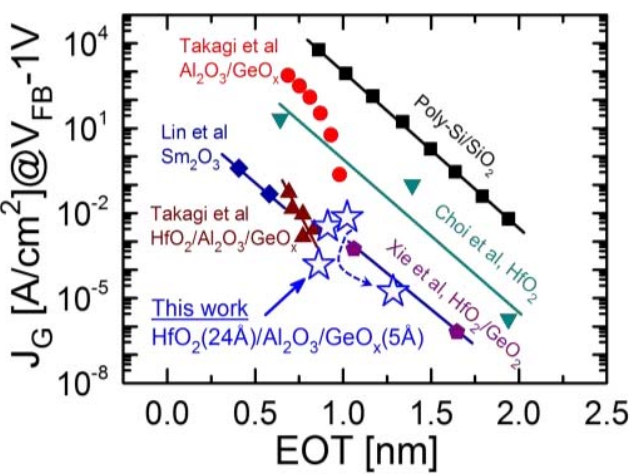

Fig. 7. Gate leakage $\left(J_{G} @ V_{F B}-1 \mathrm{~V}\right)$ vs. EOT benchmark of Ge MOSCAPs using $\mathrm{HfO}_{2}(24 \AA) / \mathrm{Al}_{2} \mathrm{O}_{3} / \mathrm{GeO}_{\mathrm{x}}(5 \AA)$ gate stacks with $0.0,2.2,4.9$, and $10.1 \AA$ $\mathrm{Al}_{2} \mathrm{O}_{3}$ (indicated by dash arrow). EOT is calculated using $C_{\text {max }} @ 1.5 \mathrm{MHz}$.

$\mathrm{Al}_{2} \mathrm{O}_{3} / \mathrm{GeO}_{\mathrm{x}}$ intermixing, which maintained a low thickness of the inter-layer between $\mathrm{HfO}_{2}$ and $\mathrm{Ge}$, but slightly contributed to the increase of its effective permittivity.

\section{CONCLUSION}

A combination of in-situ surface process and in-situ control by spectroscopic ellipsometry was used for rapid prototyping of high-k gate stacks on the challenging Ge surface. Trilayer gate stacks of $\mathrm{HfO}_{2} / \mathrm{Al}_{2} \mathrm{O}_{3} / \mathrm{GeO}_{\mathrm{x}} / \mathrm{p}-\mathrm{Ge}$ were fabricated and the functionality of individual layer was explored in details. The optimized process resulted in a superior quality of dielectric-Germanium interface, sub-nm EOT $(\sim 0.85 \mathrm{~nm})$ and low gate leakage $\left(J_{G}=0.15 \mathrm{~mA} / \mathrm{cm}^{2}\right.$ at $\left.V_{F B}-1 \mathrm{~V}\right)$ in p-Ge MOSCAP using the trilayer gate stack of $\mathrm{HfO}_{2}(24 \AA) / \mathrm{Al}_{2} \mathrm{O}_{3}(5 \AA) / \mathrm{GeO}_{\mathrm{x}}(5 \AA)$.

\section{REFERENCES}

[1] D. P. Brunco et al., "Germanium MOSFET devices: Advances in materials understanding, process development, and electrical performance," J. Electrochem. Soc., vol. 155, no. 7, pp. H552-H561, 2008.

[2] Y. Fukuda et al., "Electrical characterization of germanium oxide/germanium interface prepared by electron-cyclotron-resonance plasma irradiation," Jpn. J. Appl. Phys., vol. 44, no. 9S, pp. 6981-6984, Sep. 2005.

[3] R. Zhang et al., "High mobility Ge pMOSFETs with $0.7 \mathrm{~nm}$ ultrathin EOT using $\mathrm{HfO}_{2} / \mathrm{Al}_{2} \mathrm{O}_{3} / \mathrm{GeO}_{\mathrm{x}} / \mathrm{Ge}$ gate stacks fabricated by plasma post oxidation," in Proc. Symp. VLSI Technol., Jun. 2012, pp. 161-162.

[4] Y. Oshima et al., "Chemical bonding, interfaces, and defects in hafnium oxide/germanium oxynitride gate stacks on Ge(100)," J. Electrochem. Soc., vol. 155, no. 12, pp. G304-G309, 2008.

[5] M. Houssa et al., "First-principles study of the structural and electronic properties of $(100) \mathrm{Ge} / \mathrm{Ge}(\mathrm{M}) \mathrm{O}_{2}$ interfaces $(M=\mathrm{Al}, \mathrm{La}$, or $\mathrm{Hf}), " A p p l$. Phys. Lett., vol. 92, no. 24, p. 242101, 2008.

[6] P. Hashemi and J. L. Hoyt, "High hole-mobility strained- $\mathrm{Ge} / \mathrm{Si}_{0.6} \mathrm{Ge}_{0.4}$ P-MOSFETs with high- $k$ /metal gate: Role of strained-Si cap thickness," IEEE Electron Device Lett., vol. 33, no. 2, pp. 173-175, Feb. 2012.

[7] M. Barth et al., "High quality $\mathrm{HfO}_{2} / \mathrm{p}-\mathrm{GaSb}(001)$ metal-oxidesemiconductor capacitors with $0.8 \mathrm{~nm}$ equivalent oxide thickness," Appl. Phys. Lett., vol. 105, no. 22, p. 222103, 2014.

[8] J. Cho, T. P. Schneider, and R. J. Nemanich, "Surface electronic states of low temperature H-plasma cleaned $\mathrm{Si}(100)$ and $\mathrm{Ge}(100)$ surfaces," MRS Proc., vol. 259. 1992, p. 237.

[9] C. Förster et al., "In situ spectroscopic ellipsometry of hydrogen-argon plasma cleaned silicon surfaces," Thin Solid Films, vols. 455-456, pp. 695-699, May 2004.

[10] Q. Xie et al., "Germanium surface passivation and atomic layer deposition of high- $k$ dielectrics-A tutorial review on Ge-based MOS capacitors," Semicond. Sci. Technol., vol. 27, no. 7, p. 074012 , Jul. 2012.

[11] R. Engel-Herbert, Y. Hwang, and S. Stemmer, "Comparison of methods to quantify interface trap densities at dielectric/III-V semiconductor interfaces," J. Appl. Phys., vol. 108, no. 12, p. 124101, 2010. 